\title{
Gas6 protein: its role in cardiovascular calcification
}

\author{
Nadine Kaesler ${ }^{1 *}$, Svenja Immendorf ${ }^{1}$, Chun Ouyang ${ }^{1}$, Marjolein Herfs ${ }^{2}$, Nadja Drummen², Peter Carmeliet ${ }^{3}$, \\ Cees Vermeer ${ }^{2}$, Jürgen Floege ${ }^{1}$, Thilo Krüger ${ }^{1+}$ and Georg Schlieper ${ }^{1+}$
}

\begin{abstract}
Background: Cardiovascular calcifications can be prevented by vitamin $\mathrm{K}$ and are accelerated by vitamin $\mathrm{K}$ antagonists. These effects are believed to be mainly mediated by the vitamin K-dependent matrix Gla protein. Another vitamin K-dependent protein, Gas6, is also expressed in vascular smooth muscle cells (VSMC). In vitro Gas6 expression was shown to be regulated in VSMC calcification and apoptotic processes.

Methods: We investigated the role of Gas6 in vitro using VSMC cultures and in vivo in young and old Gas6-deficient $\left(\right.$ Gas6 $^{-1}$ ) and wildtype (WT) mice. In addition, Gas6 ${ }^{-1-}$ and WT mice were challenged by (a) warfarin administration, (b) uninephrectomy (UniNX) plus high phosphate diet, or (c) UniNX plus high phosphate plus electrocautery of the residual kidney.

Results: In vitro VSMC from WT and Gas6 ${ }^{--}$mice exposed to warfarin showed increased apoptosis and calcified similarly. In vivo, aortic, cardiac and renal calcium content in all groups was similar, except for a lower cardiac calcium content in Gas6 $^{--}$mice (group a). Von Kossa staining revealed small vascular calcifications in both WT and Gas6 ${ }^{-1-}$ mice (groups a-c). In aging, non-manipulated mice, no significant differences in vascular calcification were identified between Gas $^{-{ }^{-}}$and WT mice. Gas6 ${ }^{-1-}$ mice exhibited no upregulation of matrix Gla protein in any group. Cardiac output was similar in all treatment groups.
\end{abstract}

Conclusions: Taken together, in our study Gas6 fails to aggravate calcification against the previous assumption.

\section{Background}

Cardiovascular calcifications are highly prevalent in chronic kidney disease and are associated with an increased morbidity and mortality [1]. They can be accelerated by warfarin, a direct inhibitor of the vitamin $\mathrm{K}$ regenerating cycle [2]. Vascular calcifications occur in the arterial media and intima [3]. Vascular smooth muscle cells (VSMC) of the arterial media express two vitamin K-dependent proteins, gla rich protein [4], matrix Gla protein (MGP) [5] and Gas6 [6]. Both require reduced vitamin $\mathrm{K}\left(\mathrm{KH}_{2}\right)$ as a cofactor for posttranslational $\gamma$-carboxylation and activation. MGP potently inhibits vascular calcification via interference with hydroxyapatite crystal formation [7].

In contrast to MGP, the role of Gas6 in vascular calcification has repeatedly been suggested $[8,9]$ but

\footnotetext{
* Correspondence: nkaesler@ukaachen.de

${ }^{\dagger}$ Equal contributors

'Uniklinik RWTH Aachen, Nephrology, Aachen, Germany

Full list of author information is available at the end of the article
}

so far has remained largely speculative. Gas6 shows $40 \%$ homology to protein S; both are members of the vitamin $\mathrm{K}$ family. Protein $\mathrm{S}$ is predominantly expressed in the liver [10] whereas Gas6 is highly expressed in the kidney, heart and lungs [11]. Both proteins are ligands for the Axl tyrosine kinase receptors. These receptors regulate cell survival and apoptosis [12]. Vitamin-Kdependent carboxylation of Gas6 is essential for its binding to the Axl receptor [13]. Tyrosine phosphorylation of Axl induces cell proliferation [14]. Gas6 is known to protect endothelial cells and VSMC against apoptosis $[15,16]$, and apoptotic bodies are known to be associated with vascular calcifications. Another potential and more coherent link between Gas6 and vascular calcifications are in vitro data showing that phosphate-induced calcification of VSMC is associated with a downregulation of Gas6 expression [16]. In addition, antiapoptotic effects and protection of calcification of VSMC by statins were apparently mediated through Gas6 mRNA stabilization [16]. Also effects of 
testosterone [9], taurine [17] and adiponectin [18] in cells were linked to alterations in Gas6 expression. Binding of Gas6 by alpha lipoic acid resulted in decreased apoptosis and calcification in VSMC and mice [8]. So far no in vivo data are available on the role of Gas6 itself in cardiovascular calcification. To clarify this, we assessed Gas6 knockout $\left(\mathrm{Gas6}^{-1-}\right)$ mice and Gas6 $^{-1-}$ derived VSMC in in vitro and in vivo in cardiovascular calcification models.

\section{Methods}

\section{Animals \& diets}

$\mathrm{Gas6}^{-1-}$ mice, as described previously [19], were backcrossed for more than 10 generations onto a C57BL/6 background. They received feed and water ad libitum. Healthy, aging mice were sacrificed at the age of 34-36 weeks. For the surgical groups (uninephrectomy, UniNx or electrocautery) the rodent chow (AB diets, Woerden, the Netherlands) was supplemented to $0.95 \%$ calcium and $1.65 \%$ phosphate. The warfarin chow contained $3 \mathrm{~g} /$ $\mathrm{kg}$. The warfarin diet or surgery was started at the age of 8-10 weeks and the diets were continued for 8 weeks. UniNx was performed at the age of 8 weeks. Therefore, the left kidney was eventrated and -after ligation of the ureter with silk - fully removed. After one week of recovery, the high phosphate diet was initiated. For more severe kidney damage, electrocautery of the right kidney at the age of 8 weeks plus UniNx of the left kidney 2 weeks later were performed. Punctual lesions were set on the renal cortex with a 2-mm diameter electrocoagulation ball tip over all areas of the kidney (Erbe, Erbotom ACC 450, Tübingen, Germany). The 1-mm deep punctuate lesions were spaced $2 \mathrm{~mm}$ apart [20]. After 2 weeks, the contralateral kidney was removed and after one additional week the high phosphate diet was started (Fig. 1). In all experiments, only female animals were used, except in aging mice where both genders were analyzed (age matched). In our in vivo models 10 animals per group were used at least, except in the electrocautery group where only 4 animals could be analysed because of high mortality and 6 animals for the initial, measurements in healthy mice. All animals were treated in accordance with the requirements of the Federation of the European Laboratory Animals Science Associations. The protocol was approved by the Landesamt für Natur, Umwelt und Verbraucherschutz NRW, Germany (Permit Number 8402.04.2011.A144). All surgery was performed under ketamine/rompun anaesthesia and all efforts were made to minimize suffering.

\section{VSMC cell culture}

VSMC were isolated from the thoracic aorta of C57BL/6 and $\mathrm{Gas6}^{-1-}$ mice. After harvesting, aortas were incubated with $2 \mathrm{~g} / \mathrm{L}$ collagenase, $1 \%$ elastase for $1 \mathrm{~h}$ at $37^{\circ} \mathrm{C}$. The cell culture medium (PromoCell, Heidelberg, Germany) was supplemented with $1 \%$ penicillin streptomycin and $0.1 \%$ gentamycin. Passages from 3-5 were used for calcification experiments. Calcification medium contained 3-mM calcium phosphate or $10 \mathrm{nM}, 3 \mathrm{~m} \mathrm{M}$ calcium phosphate and $10 \mu \mathrm{M}$ warfarin or 3 and $8 \mathrm{mM}$ beta glycerolphosphate (BGP) plus $3 \mathrm{mM}$ calcium (all chemicals from Sigma Aldrich, Munich, Germany). To induce calcification, cells were cultured for 5 to 7 days with calcification medium. A negative control $\left(\mathrm{d}_{0}\right)$ was included in each setup to normalize the obtained values and calcium deposits were depicted as $\mathrm{mg} / \mathrm{g}$ total protein.

\section{Cardiovascular parameters}

Transthoracic echocardiography was performed on the Vevo 770 (Visualsonics, Ontario, Canada). Therefore, mice were anesthetised with isoflurane (Abbott, IL, USA) and

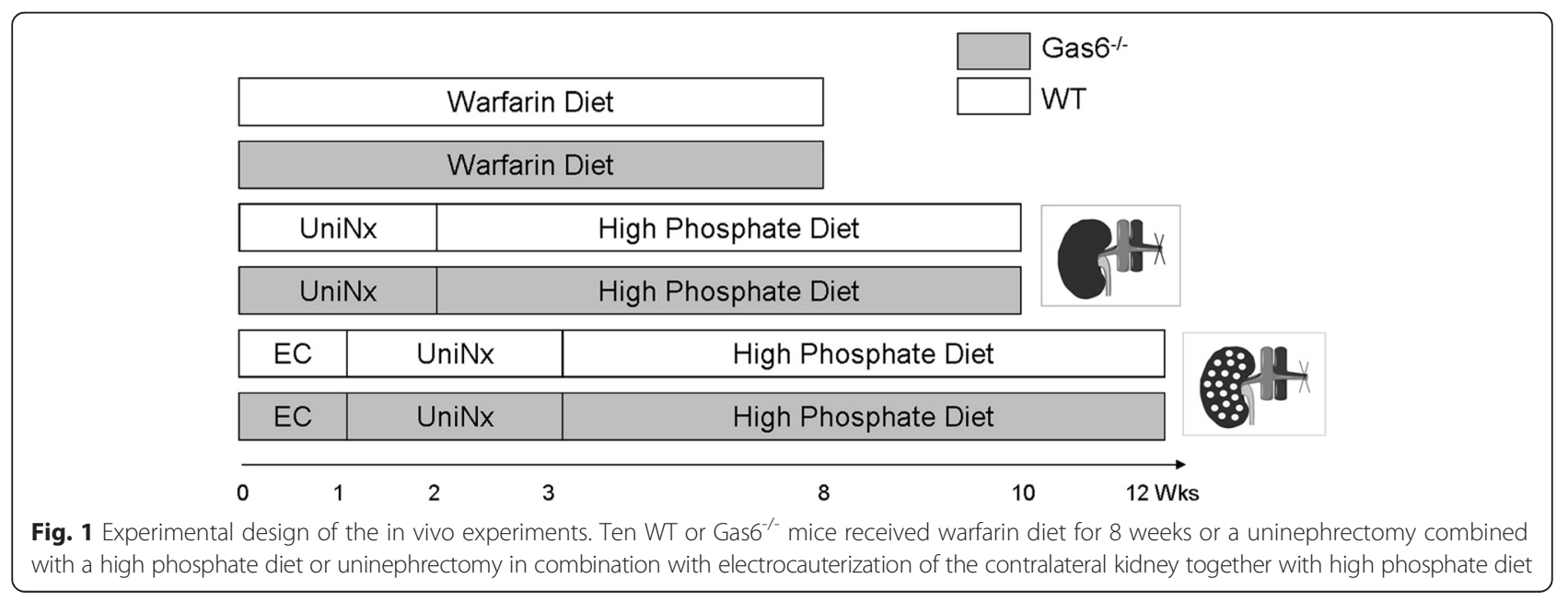


placed on a warming plate at $37{ }^{\circ} \mathrm{C}$. Breathing and heart frequency were monitored continuously. Left ventricular (LV) mass was calculated in the M-mode in the long axis view from the Devereux formula. Ejection fraction (EF) as an index for global left ventricular systolic function were measured by the Simpson's method. Stroke volume was estimated as the difference between the LV end-systolic and end-diastolic volumes. Pulse-wave velocity in the right common carotid artery and the abdominal aorta were measured using the transit-time method in a two-dimensional mode. In the carotid artery, the proximal pulse-wave signal was obtained $1 \mathrm{~mm}$ behind the origin of the subclavian artery, the distal signal $1 \mathrm{~mm}$ before the carotid bifurcation. The transit time was found by subtracting the distal arrival time between the ECG R-wave peak and the foot of velocity upstroke from the similarly determined proximal arrival time $\left[\mathrm{PWV}=\Delta \mathrm{d} /\left(\mathrm{Pt}_{\mathrm{dist}}-\mathrm{Pt}_{\mathrm{prox}}\right)\right]$, where $\mathrm{Pt}$ is the time point of the proximal or distal pulse- wave signal and $\Delta \mathrm{d}$ is the distance between the two measurements.

\section{Biochemistry}

Blood was collected by puncture of the left ventricle, terminally. After sedimentation, serum was obtained by centrifugation at $2000 \times \mathrm{g}$ for $10 \mathrm{~min}$. Urine was collected for $24 \mathrm{~h}$ before sacrifice. Serum and urine parameters were measured by clinical routine laboratory diagnostics (Vitros 250, Ortho Clinical Diagnostics, NY, USA).

Protein content was measured by the Pierce Bicinchoninic Acid method, as described by the manufacturer (Thermo Fisher Scientific, IL, USA) [21].

Additionally, the murine serum was tested by total ucMGP ELISA (VitaK BV, Maastricht, the Netherlands) [22] and protein $S$ ELISA Kit (antibodies online, ABIN628120, Aachen, Germany).

\section{RT-PCR}

Genotyping of knockout animals and VSMCs was performed as described previously [23].

RNA was isolated from RNAlater stabilized aortic tissue (liver, abdominal aorta) (QIAGEN Rneasy, Hilden, Germany). Purity and RNA concentration were analyzed with the Agilent RNA 6000 Nano Kit (Agilent, Böblingen, Germany). The reverse transcriptase was performed by the Reverse Transcriptase Core Kit (RT-RTCK-05, Eurogentec, Cologne, Germany). Quantification of MGP gene expression was performed on an Applied Biosystems 7500 RealTime PCR TagMan ${ }^{\circ}$ system with external standards for MGP $\left(8.8 * 10^{6}-8.8 * 10\right)$ and GAPDH $\left(6.4 * 10^{6}-6.4 *\right.$ 10). MGP probe was 5'AGAGTCCAGGAACGCAACAA GCCTGC 3', sense primer 5' GCAGAGGTGGCGAGC TAAAG 3' and antisense primer 5' AGCGCTCACAC AGCTTGTAGTC 3'. Cbfal sense primer was 5' CAAGT AGCCAGGTTCAACGATCT 3', cbfal antisense 5' GAC
TTGTATGGTCAAGGTGAAACTCTT 3'; OPN sense 5' GACCATGAGATTGGCAGTGATTT 3', OPN antisense 5' GATCTGGGTGCAGGCTGTAAAG, Axl sense 5' TCTGGCTGGGAAAGTCAGAT 3', Axl antisense 5' CAGCCGAGGTATAGGCTGTC 3' [24]. GAPDH probe was 5' AAGGCCGAGAATGGGAAGCTTGTCATC 3', sense primer 5' AAGTGGTGATGGGCTTCCC 3' and antisense primer 5' GGCAAATTCAACGGCACAGT 3'.

\section{Calcium measurement}

Tissue calcium content was measured with the cresolphthalein assay. Tissues (kidney, heart, aortic arch) were lyophilisated on a Christ Loc 1mALPHA 1-4 (Martin Christ, Osterode am Harz, Germany) coupled with a vacuum hybrid pump RL 6 (Vacuubrand, Wertheim, Germany). Calcium was mobilised in $10 \%$ formic acid and quantified by the cresolphthalein method (Randox Laboratories, Crumlin, UK). Absorption was measured at $550 \mathrm{~nm}$ on a Tecan Sunrise microplate absorbance reader (Tecan, Mennedorf, Switzerland).

\section{Histochemistry}

Localisation of phosphate crystals was analyzed by von Kossa staining [25, 26] (kidney, heart base, descending aorta). Sirius red staining was performed in heart tissues by $5 \%(w / v)$ Sirius red (Sigma Aldrich, Munich, Germany) in picric acid (Sigma Aldrich, Munich, Germany) followed by washing in acidified ethanol (70 \% (v/v); pH 3.5). Apoptosis measurements were performed with the in situ cell death detection kit (Roche, Ref. 11684817910, Basel, Switzerland) according to the manufacturer's protocol. Cells were counterstained with DAPI (Vectashield, Vector Laboratories, CA, USA). Apoptosis was quantified by counting TUNEL positive VSMCs and by planimetric analysis in aortic sections (Keyence BZ-II Analyzer, Neu-Isenburg, Germany).

\section{Statistics}

Differences between treatment groups were assessed by one-way ANOVA followed by Tukey's multiple comparison test. Equal variances were tested with Bartlett's method. D'Agostino and Pearson normality test was performed to check for Gaussian distribution. Statistical significance was defined as $p<0.05$, highly significant $p<0.001$. Comparison between only two groups was performed by Students $t$-test in WT and knockout animals after different treatment periods.

\section{Results}

\section{In vitro VSMC calcification}

In vitro, VSMC of WT and $\mathrm{Gas}^{-1-}$ mice were challenged by calcification medium or by warfarin. Using calcification medium, the deposition of calcium in VSMC increased over time: though in early stages not significant, 
after $120 \mathrm{~h}$ the calcium content had increased 4-fold in WT and 1.4-fold in Gas6 ${ }^{-1-}$ VSMC (Fig. 2a). After $168 \mathrm{~h}$ of incubation, the calcium load of VSMC increased further (significant for WT cells compared to $0 \mathrm{~h}$ ). There was no significant difference between VSMC from Gas6 $^{-1-}$ and WT mice (Fig. 2).

Warfarin treatment at a low dosage of $10 \mathrm{nM}$ significantly increased calcium deposition in WT cells after 120 h (WT t t20 + $648 \% \pm 540 \%$ change in calcium deposition). Again, we could not observe a significant difference in calcium load between $\mathrm{Gas}^{-1-}$ and WTderived VSMC (data not shown). Calcium phosphate load led to an increased calcium deposition in WT cells and the highest dosage of $10 \mu \mathrm{M}$ of warfarin significantly increased calcium deposition after $120 \mathrm{~h}$ in Gas6 $^{-1-}$ cells (Fig. 3).

Treatment with $3 \mathrm{mM}$ BGP significantly increased calcium deposits only in WT-VSMC after 120 h. Cadeposition at $8 \mathrm{mM}$ BGP was similar in $\mathrm{Gas6}^{-/-}$and WT VSMC (data not shown).

The rate of VSMC apoptosis in calcification medium increased significantly at $120 \mathrm{~h}$ and $168 \mathrm{~h}$ in WT cells.
The rate of apoptosis was not different in $\mathrm{Gas6}^{-/-} \mathrm{com}$ pared to WT VSMC (Fig. 2b).

\section{In vivo calcification models \\ Young healthy mice}

In vivo, we first compared untreated animals of both groups (Gas6 $6^{-1-}$ and WT). At the age of 8 weeks, out of a number of serum parameters, only alkaline phosphatase was lower in healthy $\mathrm{Gas6}^{-/-}$than in WT mice (Table 1). Echocardiography revealed a lower LV mass in healthy WT mice compared to healthy $\mathrm{Gas6}^{-/-}$at the age of 8 weeks (Table 1 ).

We next tested whether in Gas6 $^{-1-}$ mice upregulation of the calcification inhibitor MGP occurred. However, in $\mathrm{Gas6}^{-1-}$ mice MGP gene expression and serum undercarboxylated MGP (ucMGP) levels were equal to WT (Fig. 4). Similarly, serum levels of circulating protein $\mathrm{S}$, which shows a $43 \%$ homology with Gas6 [10], did not differ between the mouse strains (Table 1). Expression of the osteoblastic marker osteopontin was absent in aortas from healthy WT mice and low in Gas6 $^{-/-}$mice (Fig. 5).

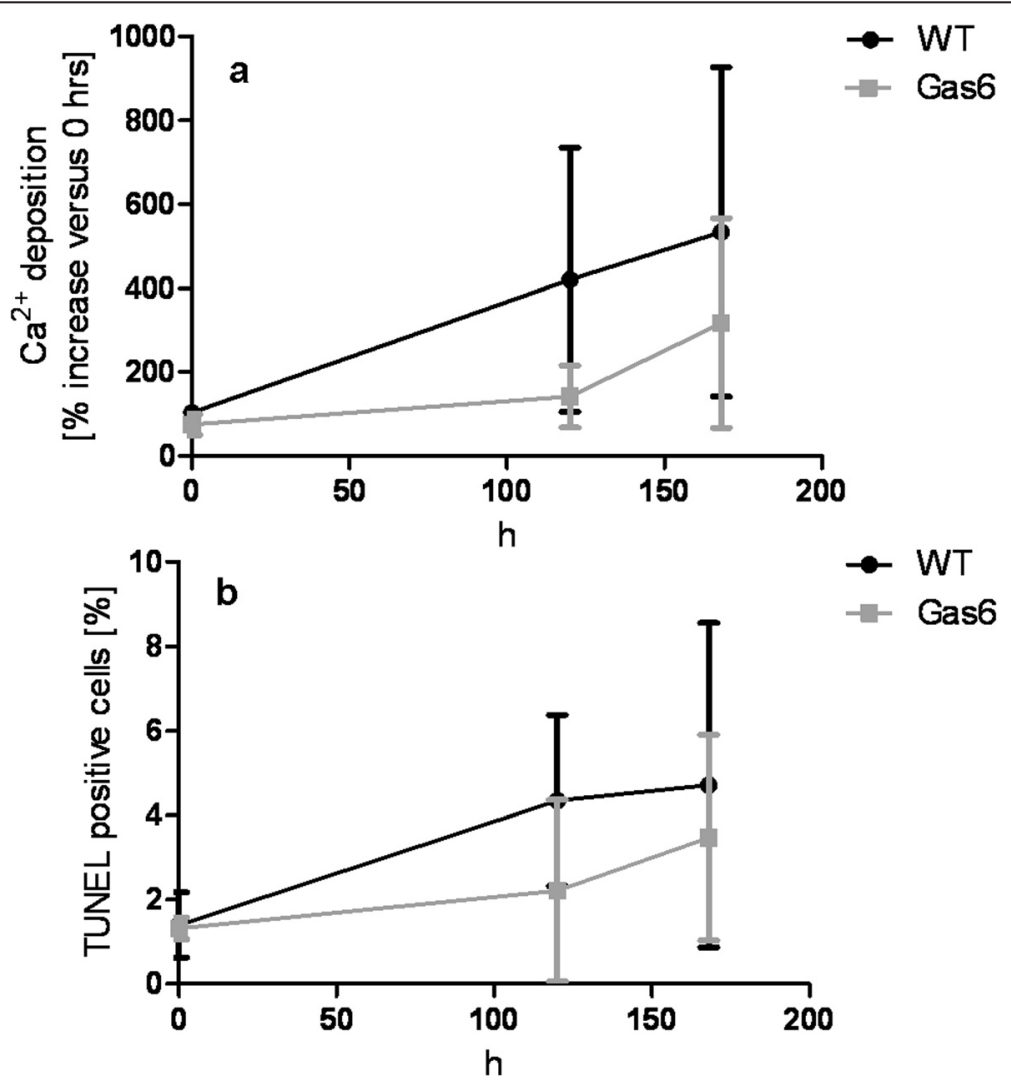

Fig. 2 Calcium deposition a Ca ${ }^{2+}$ deposition in VSMC derived from $\mathrm{Gas}^{-/-}$and WT mice after $168 \mathrm{~h}$ (h) of exposure to phosphate and calcium-enriched cell culture medium. $\mathbf{b}$ TUNEL-positive VSMC of Gas6 and WT mice after exposure to phosphate and calcium-enriched cell culture medium. VSMC (Vascular Smooth Muscle Cells), WT (Wildtype); mean \pm SD; *: the increase in apoptosis was significant for WT cells after $120 \mathrm{~h}$ and $168 \mathrm{~h}$ compared to $0 \mathrm{~h}(p<0.05)$; ** the increase in calcification was highly significant for WT cells after $168 \mathrm{~h}$ compared to $0 \mathrm{~h}(p<0.001)$ 


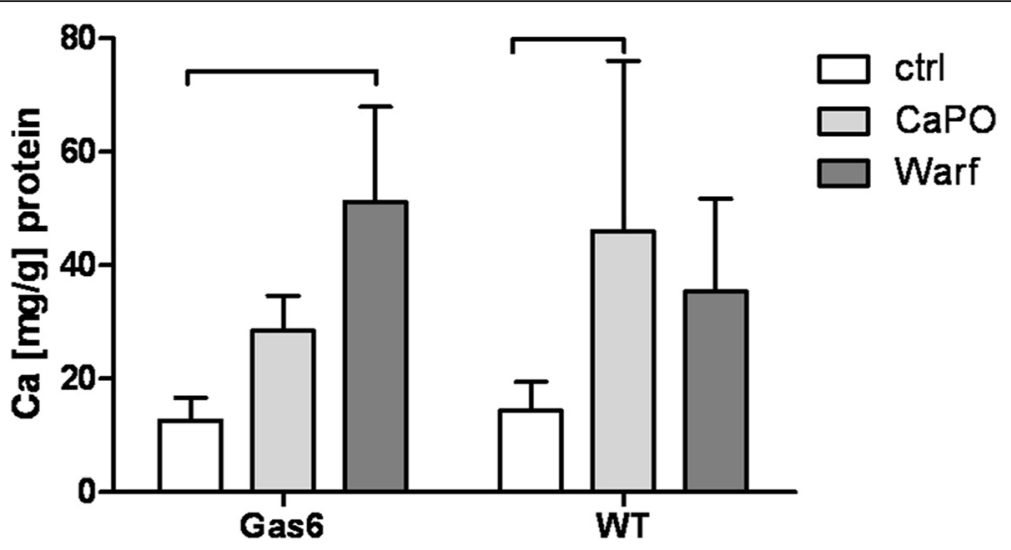

Fig. 3 Calcium deposition a) $\mathrm{Ca}^{2+}$ deposition in VSMC isolated from WT and Gas6 ${ }^{-1-}$ mice after treatment with calcium phosphate and warfarin over 5 days; mean \pm SD. *: $p<0.05$; * $: p<0.001$

\section{Older mice}

Second, 34-36 week old mice were also assessed. Whereas total serum protein was lower in $\mathrm{Gas6}^{-1-}$ mice, all other serum parameters were comparable (Table 1). Calcium content of the aortas, hearts and kidneys was not significantly different between older $\mathrm{Gas}^{-/-}$and WT mice (Fig. 6a-c). Von Kossa staining revealed only minor calcifications in both groups without significant differences. No differences in apoptosis rates in aortas were observed (data not shown).

In older Gas $^{-1-}$ mice MGP gene expression and serum ucMGP level were equal to older WT (Table 1). No differences were found in protein $S$ levels as well (Table 1). There was no difference in Gas6 expression during aging. Cbfa1, Axl and OPN (Fig. 5) expression was similar between Gas6 $^{-/-}$and WT mice (Fig. 7).

\section{Warfarin treatment}

Third, warfarin administration was used to induce calcification by blocking the posttranslational activation of MGP and potentially Gas6. All mice survived warfarin treatment. Serum total protein levels increased significantly in both mouse strains. No significant differences in soft tissue calcification were detected between WT and $\mathrm{Gas6}^{-1-}$ mice (Fig. 6a), except for a lower cardiac calcium content in $\mathrm{Gas}^{-1-}$ mice after 8 weeks of warfarin (Fig. 6b).

Table 1 Basal biochemistry and echocardiography

\begin{tabular}{|c|c|c|c|c|}
\hline \multirow[b]{2}{*}{ Parameter } & \multicolumn{2}{|c|}{ 8-9 weeks old, healthy } & \multicolumn{2}{|c|}{ 34-36 weeks old, healthy } \\
\hline & $\mathrm{C} 57 \mathrm{BL} / 6$ & $\mathrm{Gas6}^{-/-}$ & C57BL/6 & Gas6 $^{-/-}$ \\
\hline Body weight [g] & $20.2 \pm 0.7$ & $18.6 \pm 1.6$ & $30.1 \pm 6.4$ & $26.4 \pm 4.2$ \\
\hline \multicolumn{5}{|l|}{ Serum parameter } \\
\hline Urea [mmol/l] & $10.8 \pm 3.3$ & $11.6 \pm 1.9$ & $6.6 \pm 1$ & $6.0 \pm 0.9$ \\
\hline Creatinine $[\mu \mathrm{mol} / \mathrm{l}]$ & $19.6 \pm 2.1$ & $24.5 \pm 8.6$ & $18.0 \pm 5.9$ & $26.2 \pm 16.7$ \\
\hline Calcium $[\mathrm{mmol} / \mathrm{l}]$ & $2.48 \pm 0.10$ & $2.23 \pm 0.08$ & $2.39 \pm 0.13$ & $2.39 \pm 0.09$ \\
\hline Phosphate [mmol/l] & $3.11 \pm 0.91$ & $3.05 \pm 0.82$ & $2.88 \pm 0.45$ & $2.85 \pm 0.34$ \\
\hline Protein [g/dl] & $4.46 \pm 0.74$ & $4.90 \pm 0.15$ & $6.00 \pm 0.42$ & $5.50 \pm 0.26^{*}$ \\
\hline Alkaline phosphatase [U/l] & $255 \pm 106$ & $256 \pm 35$ & $142 \pm 54$ & $207 \pm 69$ \\
\hline ucMGP [nM] & $3158 \pm 458$ & $2987 \pm 554$ & $3523 \pm 1645$ & $3532 \pm 1095$ \\
\hline Protein S [ng/ml] & $0.97 \pm 0.24$ & $0.87 \pm 0.16$ & $0.80 \pm 0.14$ & $0.72 \pm 0.14$ \\
\hline \multicolumn{5}{|l|}{ Echocardiography } \\
\hline Left ventricular mass [mg] & $50.8 \pm 11.4$ & $73.6 \pm 9.8^{*}$ & $98.6 \pm 15.2$ & $81.8 \pm 29.5$ \\
\hline Stroke volume $[\mu l]$ & $23.9 \pm 9.0$ & $20.3 \pm 6.3$ & $23.6 \pm 6.2$ & $19.8 \pm 4.3$ \\
\hline Ejection Fraction [\%] & $54.3 \pm 11$ & $45.6 \pm 7.8$ & $40.1 \pm 9.6$ & $41.5 \pm 11.0$ \\
\hline VACC $[\mathrm{mm} / \mathrm{ms}]$ & $2.09 \pm 0.98$ & $2.06 \pm 1.15$ & $2.13 \pm 1.52$ & $1.72 \pm 0.72$ \\
\hline
\end{tabular}

Baseline biochemical and functional characteristics of healthy wildtype and Gas $6^{-/-}$mice at different ages (Mean \pm SD), ucMGP uncarboxylated matrix Gla protein, $V_{A C C}$ pulse-wave velocity over the common carotid artery, $W T$ wildtype ${ }^{*} p<0.05$ to corresponding wildtype control 


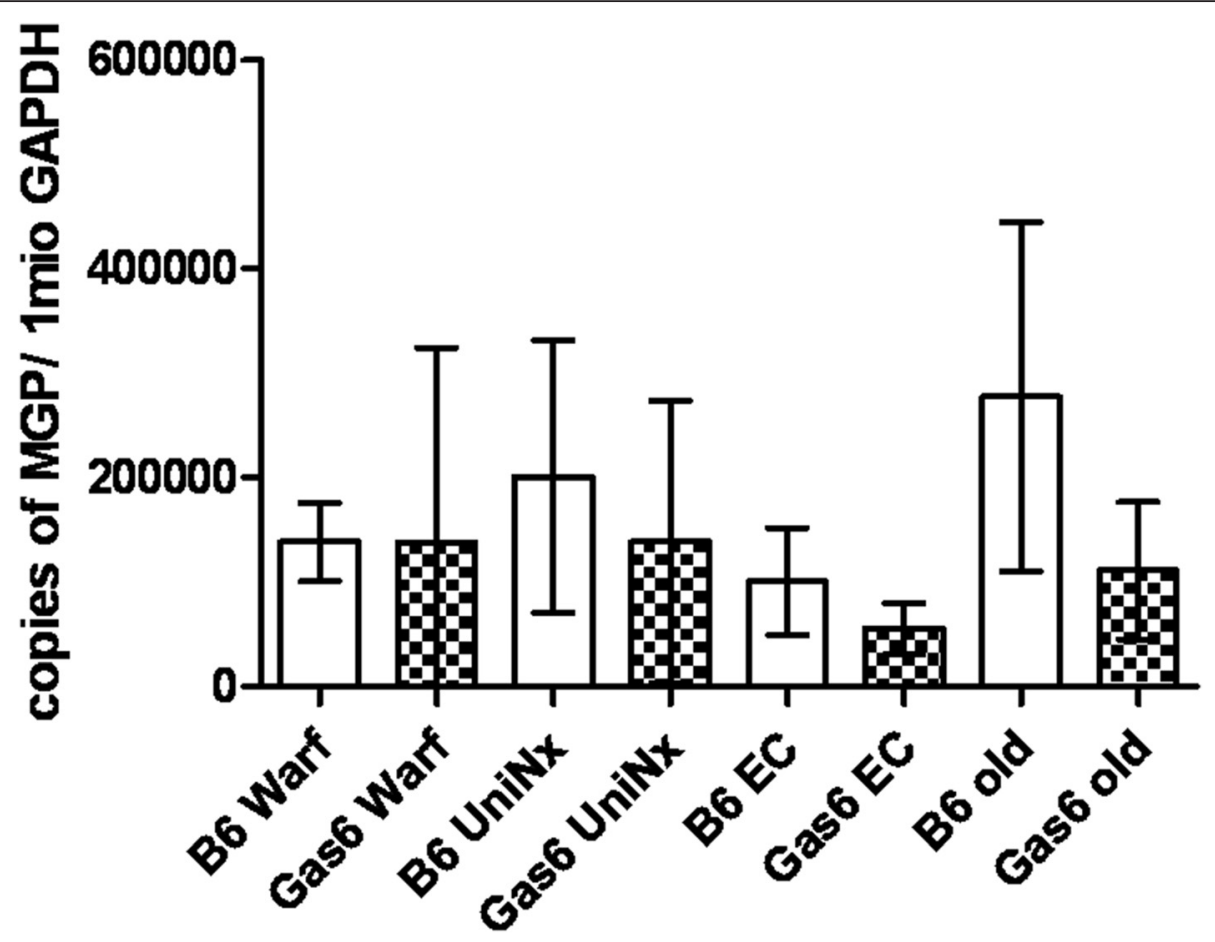

Fig. 4 MGP expression; MGP mRNA expressed as copies of MGP per 1 million copies of GAPDH measured by RT-PCR; mean \pm SD

As calcium content in WT mice after warfarin diet was higher only in cardiac tissue compared to $\mathrm{Gas}^{-1-}$ mice, and data from the literature reported that calcification appears in the vicinity of collagen fibres [27] and Gas6 deficiency prevents fibrosis [28] we tested for differences in the cardiac collagen content by Sirius red staining. However, collagen-positive areas in cardiac tissues were equal in warfarin-treated mice in $\mathrm{Gas}^{-1-}$ and WT mice. Serum levels of ucMGP after warfarin diet did not show a significant difference between WT and Gas6 $^{-1-}$ mice (Table 2). No differences were found in protein $\mathrm{S}$ (Table 2) in serum. No aortic apoptosis could be detected in either of the groups. Cbfa1, Axl and OPN (Fig. 5) expression were similar in Gas6 $^{-1-}$ and WT mice (Fig. 7).

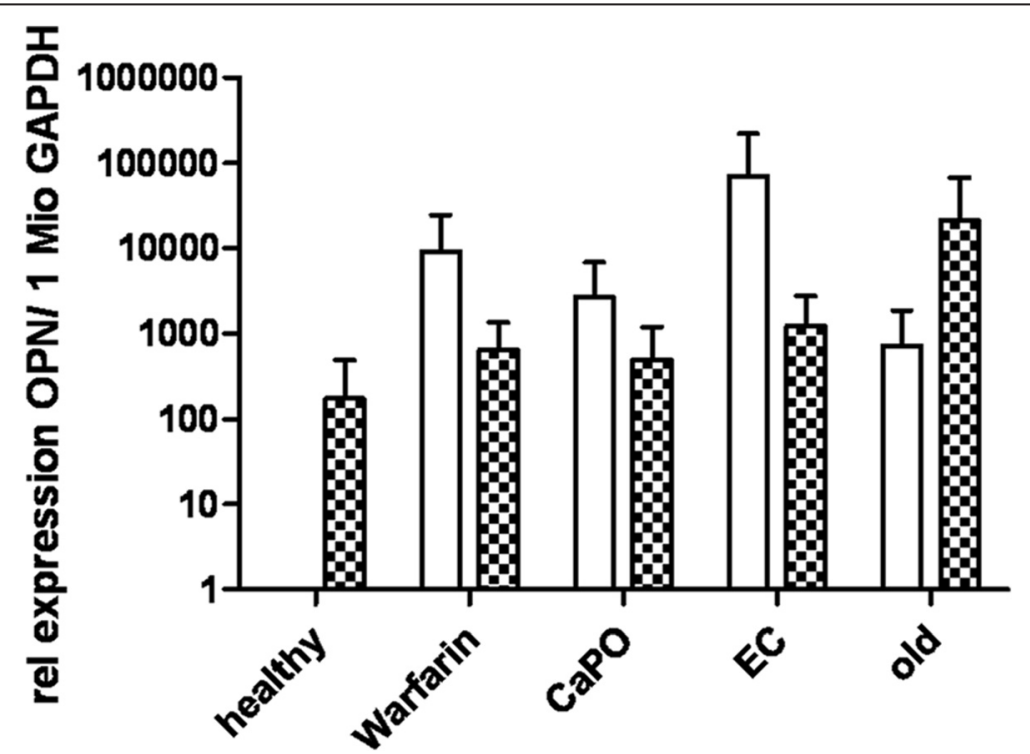

Fig. 5 Osteopontin expression; Osteopontin mRNA expressed as relative expression per 1 million copies of GAPDH measured by RT-PCR; mean \pm SD 


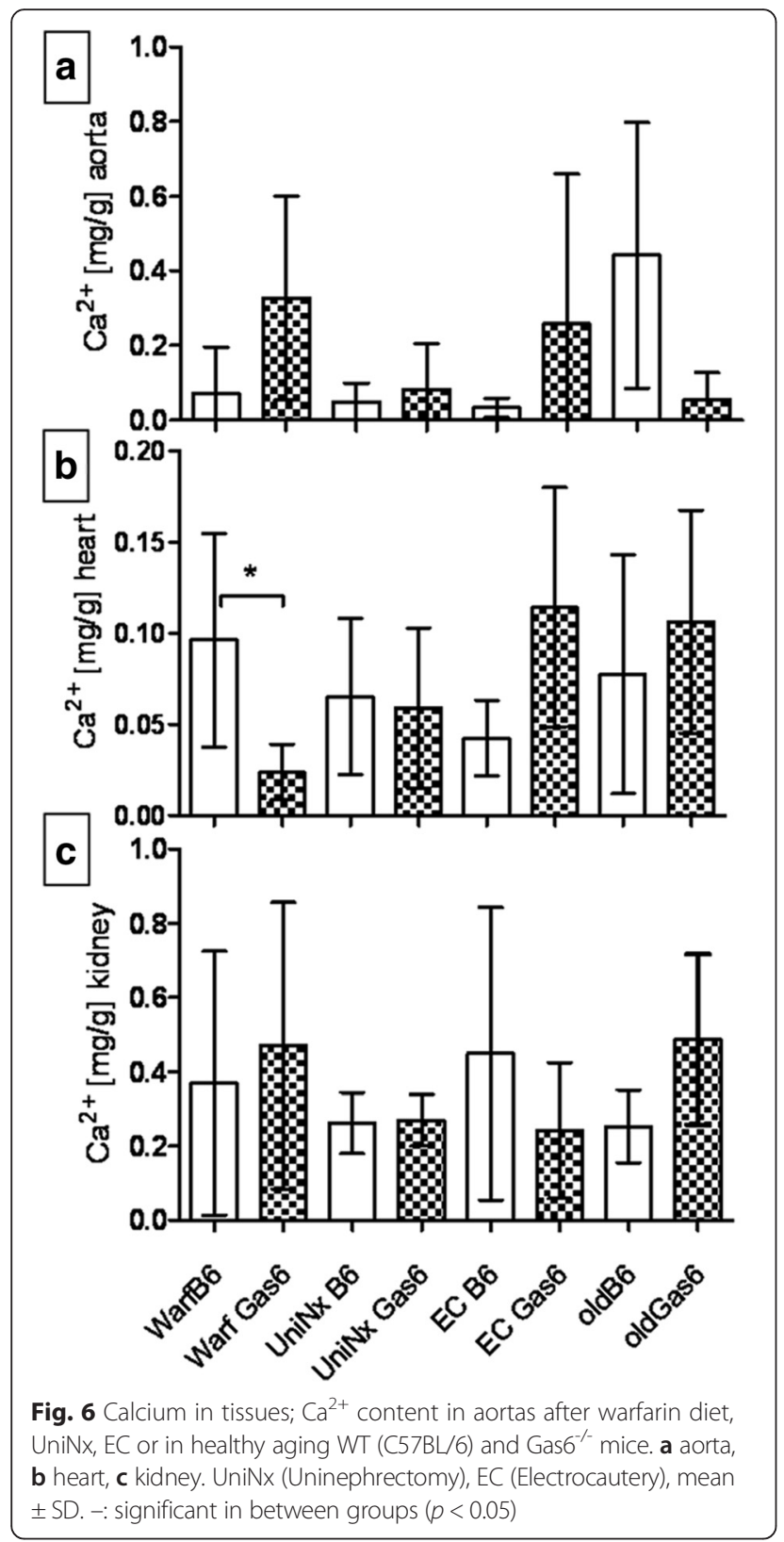

\section{Uninephrectomy}

Fourth, UniNx (plus high phosphate diet) was used to initiate kidney damage. In both UniNx groups, $15-18 \%$ of the mice died. Early death occurred in 2 of 13 in the Gas6 $^{-/-}$mice during anaesthesia and in 2 of $11 \mathrm{WT}$ mice. In WT mice one animal died during surgery and the other one 3 weeks after surgery. Serum creatinine increased after surgery, compared to healthy animals, in $\mathrm{Gas}^{-1-}$ and WT mice $\left(+46 \%\right.$ in WT and $+24 \%$ in $\mathrm{Gas}^{-1-}$, respectively) (Table 2). Spotty calcification was present in the aorta (Fig. 8a) and in cardiac tissue, however, without obvious differences between Gas6 $^{-1-}$ and WT mice (Fig. 6b). Within the heart, calcifications mainly located to the valves (Fig. 8b). The most prominent calcification was found in kidney tissues in both strains, spreading throughout all structures with accumulation in the renal cortex (Fig. 8c). Again, there was no significant difference between the two mouse strains with respect to tissue calcium content (Fig. 6a-c).

Echocardiography after UniNx revealed decreased ejection fractions in WT compared to Gas6 $6^{-/-}$(Table 2). Ejection fraction and stroke volume were lower in both strains than in healthy controls. No aortic apoptosis could be detected in both groups. In $\mathrm{Gas}^{-/-}$mice MGP gene expression, serum ucMGP and protein $\mathrm{S}$ levels were equal to WT (Table 2). Cbfa1 expression significantly increased in Gas6 $^{-1-}$ compared to WT mice, however this could not be observed in the electrocautery group. Axl and OPN (Fig. 5) expression were similar between $\mathrm{Gas6}^{-/-}$and WT mice (Fig. 7).

\section{Electrocautery}

Finally, electrocautery of the contralateral kidney was used in addition to UniNx (plus high phosphate diet) to further increase the extent of kidney damage. In the electrocautery group, all WT mice survived the surgical protocol, however, the Gas $6^{-1-}$ mice, showed decreased survival without detectable change in body weight relatively early after surgery, and only $40 \%$ survived to the end of the experiment (Fig. 9), thus all data below have to be interpreted with this caveat in mind. No obvious cause for the high mortality could be identified.

Serum calcium, phosphate and creatinine were significantly increased in WT and surviving $\mathrm{Gas}^{-1-}$ mice after electrocautery compared to the corresponding healthy controls (Table 2). Calcium content in the aortas and hearts of $\mathrm{Gas}^{-1-}$ mice was slightly higher than in WT, however, without a significant difference (Fig. 6). Calcification spots were found in a similar pattern as after UniNx in all kidney structures in both WT and Gas6 $6^{-1-}$ mice.

Electrocautery decreased ejection fraction and stroke volume only significantly in WT mice (Table 2). No relevant aortic apoptosis could be detected in either of the groups. In $\mathrm{Gas}^{-1-}$ mice aortic MGP gene expression (Table 2), serum ucMGP and protein $\mathrm{S}$ level were equal to WT (Table 2). Cbfa1, Axl and OPN (Fig. 5) expression were similar in Gas6 $^{-/-}$and WT mice (Fig. 7).

\section{Discussion}

Gas6 has repeatedly been suggested to mediate vitamin $\mathrm{K}$ effects in vascular calcification in addition to MGP. To evaluate the role of Gas6 protein in vascular calcification, we compared mice deficient in Gas6 protein with WT mice. VSMC and mice were exposed to different calcification and kidney disease models.

The major finding of this study is that both in vitro and in vivo vascular as well as organ calcification of WT and $\mathrm{Gas6}^{-/-}$mice were not different. Previously, Gas6 

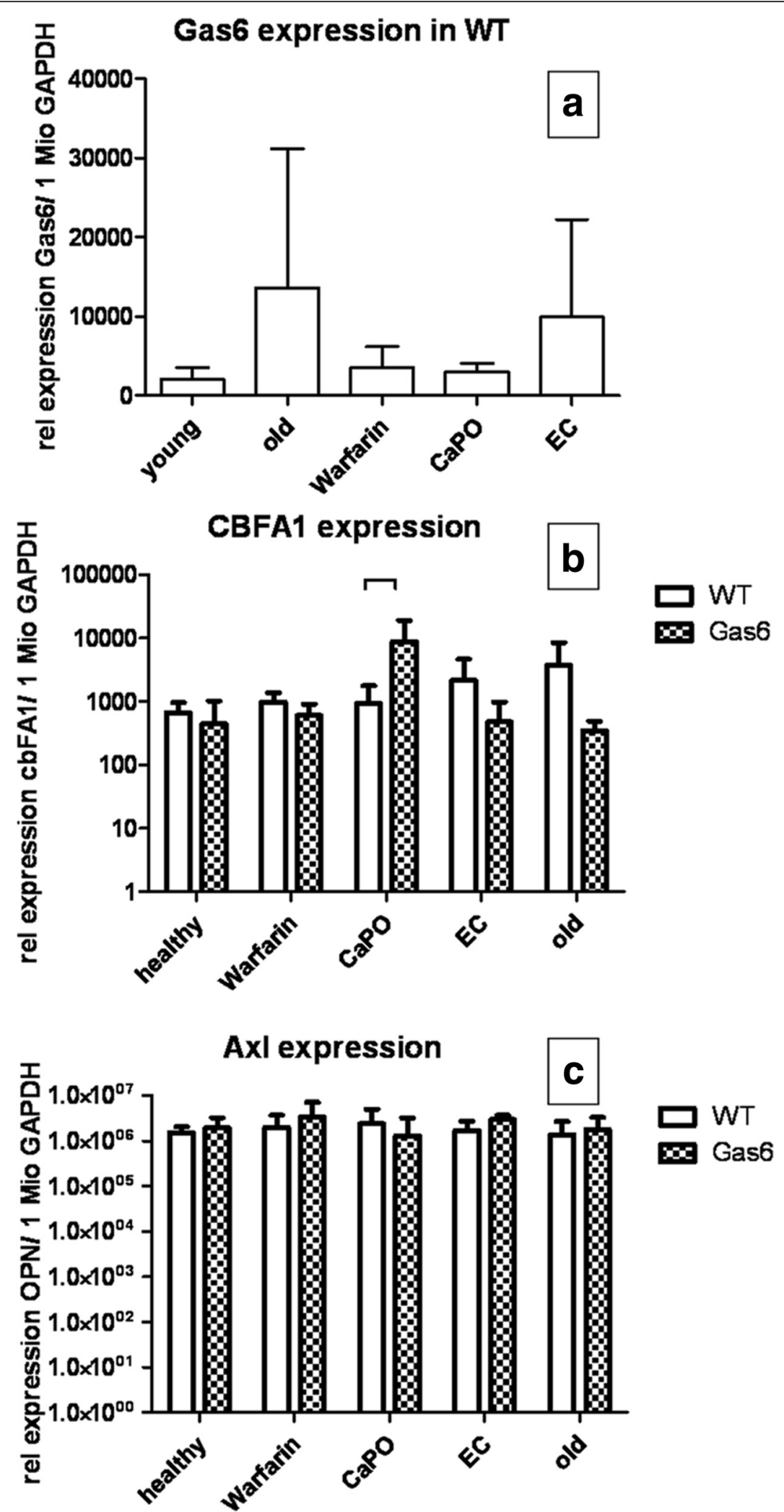

Fig. 7 Gene expression; Relative expression of Gas6 in WT (wildtype) (a); cbfa1 (b) and Axl (c) expression in WT and Gas6 ${ }^{-/-}$mice per 1 million copies of GAPDH measured by RT-PCR; mean \pm SD 
Table 2 Final biochemistry and echocardiography

\begin{tabular}{|c|c|c|c|c|c|c|}
\hline \multirow{2}{*}{$\begin{array}{l}\text { Parameter } \\
\text { Model }\end{array}$} & \multicolumn{3}{|l|}{ C57BL 16} & \multicolumn{3}{|l|}{$\mathrm{Gas6}^{-1-}$} \\
\hline & Warfarin & UniNx & Electrocautery & Warfarin & UniNx & Electrocautery \\
\hline Body weight [g] & $22.9 \pm 1.6$ & $24.4 \pm 2.2^{* * *}$ & $22.3 \pm 1.6$ & $19.1 \pm 1.7$ & $19.1 \pm 3.2^{*}$ & $18.5 \pm 3.0$ \\
\hline \multicolumn{7}{|l|}{ Serum parameter } \\
\hline Urea $[\mathrm{mmol} / \mathrm{l}]$ & $6.27 \pm 0.63^{* * *}$ & $10.26 \pm 3.58$ & $10.58 \pm 1.62$ & $6.43 \pm 1.29$ & $10.25 \pm 2.56$ & $17.1 \pm 11.58$ \\
\hline Creatinine $[\mu \mathrm{mol} / \mathrm{l}]$ & $22.0 \pm 1.7$ & $25.1 \pm 2.4^{* * * *}$ & $30.3 \pm 3.7^{* * * *}$ & $23.6 \pm 6.32$ & $29.9 \pm 14$ & $30.3 \pm 3.8$ \\
\hline Calcium $[\mathrm{mmol} / \mathrm{l}]$ & $2.58 \pm 0.09$ & $2.50 \pm 0.12$ & $2.73 \pm 0.14^{* * *}$ & $2.67 \pm 0.17$ & $2.50 \pm 0.12$ & $2.84 \pm 0.27^{* * *}$ \\
\hline Phosphate $[\mathrm{mmol} / \mathrm{l}]$ & $2.84 \pm 0.22$ & $2.78 \pm 0.29$ & $2.90 \pm 0.30$ & $3.68 \pm 0.60$ & $3.47 \pm 0.89$ & $3.91 \pm 0.68$ \\
\hline Protein [g/dL] & $6.58 \pm 0.38^{* * *}$ & $5.74 \pm 0.74^{* * * *}$ & $5.47 \pm 0.49^{* * *}$ & $6.03 \pm 0.32^{* * *}$ & $5.70 \pm 0.31^{* * *}$ & $5.41 \pm 0.55$ \\
\hline Alkaline phosphatase [U/I] & $205 \pm 27$ & $173 \pm 65$ & $166 \pm 36$ & $228 \pm 46$ & $201 \pm 64$ & $187 \pm 74$ \\
\hline ucMGP [nM] & $5374 \pm 1368$ & $4369 \pm 855$ & $3810 \pm 1283$ & $5963 \pm 2612$ & $4903 \pm 1688$ & $4970 \pm 489$ \\
\hline Protein S [ng/ml] & $1.05 \pm 0.19$ & $0.80 \pm 0.12$ & $0.72 \pm 0.03$ & $0.83 \pm 0.24$ & $0.83 \pm 0.23$ & $0.83 \pm 0.27$ \\
\hline \multicolumn{7}{|l|}{ Echocardiography } \\
\hline Left ventricular mass [mg] & $79.0 \pm 22$ & $60.7 \pm 15$ & $59.1 \pm 12$ & $69.2 \pm 14.7$ & $74.1 \pm 28.5$ & $61.4 \pm 16.6$ \\
\hline Stroke volume $[\mu l]$ & $22.0 \pm 6.0$ & $13.4 \pm 2.7$ & $10.4 \pm 2.8$ & $20.6 \pm 4.3$ & $24.4 \pm 8.9$ & $10.2 \pm 6.2$ \\
\hline Ejection Fraction [\%] & $46.6 \pm 11.6$ & $33.3 \pm 13.8$ & $33.7 \pm 7.4$ & $44.8 \pm 2.6$ & $58.4 \pm 21^{*}$ & $38.4 \pm 18$ \\
\hline VACC $[\mathrm{mm} / \mathrm{ms}]$ & $1.97 \pm 0.71$ & $2.69 \pm 1.01$ & $1.78 \pm 0.46$ & $2.26 \pm 2.14$ & $3.03 \pm 1.38$ & $1.98 \pm 0.37$ \\
\hline \multicolumn{7}{|l|}{24 h urine } \\
\hline $\mathrm{GFR}[\mu \mathrm{L} / \mathrm{min}]$ & $76.9 \pm 36.9$ & $55.2 \pm 32.4$ & $41.7 \pm 21.3$ & $56.6 \pm 32.8$ & $41.6 \pm 28.1$ & $40.4 \pm 13.0$ \\
\hline Protein [mg/dl] & 26. \pm 17 & $13 \pm 4.6^{* * *}$ & $6.7 \pm 1.9^{* * *}$ & $14.0 \pm 4.9$ & $9.5 \pm 6^{* * *}$ & $17.7 \pm 4.2$ \\
\hline Creatinine $[\mu \mathrm{mol} / \mathrm{l}]$ & $2071 \pm 2005$ & $3853 \pm 2520$ & $3062 \pm 1133$ & $4283 \pm 3853$ & $2175 \pm 667$ & $914 \pm 179$ \\
\hline
\end{tabular}

${ }^{*} p<0.05$ to corresponding wildtype group ${ }^{* * *} p<0.05$ to healthy control group ${ }^{* * *} p<0.001$ to healthy control group

Biochemical and functional characteristics of wildtype and Gas $^{-/-}$after 8 weeks of treatment (Mean \pm SD), GFR glomerular filtration rate, ucMGP uncarboxylated matrix Gla protein, UniNx uninephrectomy, VACC pulse-wave velocity over the arteria carotis communis)

mRNA stabilisation was found to be a protective mechanism of statins in cell culture experiments [16]. In these in vitro experiments, Gas6 mediated protection against calcification. However, these findings were obtained only in vitro and in contrast to the present study, no in vivo verification was attempted.

Transformation of VSMC into an osteoblastic phenotype is a highly regulated process. Among others, the vitamin K-dependent protein MGP [29] and apoptosis, in particular apoptotic bodies [30,31], have been shown to play important roles in the calcification process. The vitamin K-dependent protein Gas6 reportedly mediates anti-apoptotic effects [15] and could thereby conceivably prevent calcification like MGP. However, here we failed to observe increased apoptosis in $\mathrm{Gas6}^{-1-}$ mice in vivo and in vitro when compared to WT mice and we thus cannot confirm a role of Gas6 in an anti-apoptotic pathway in our uremia and calcification models.

To test for other potential counterregulatory mechanisms against calcification in the $\mathrm{Gas6}^{-1-}$ mice that might have compensated for the lack of Gas6 functions, we analyzed MGP gene expression, ucMGP staining in the aorta and ucMGP serum levels. MGP is known to be the most important local calcification inhibitor in the vessel wall [7]. MGP, like Gas6, is vitamin K dependent for bioactivity and could act as a compensatory mechanism for the lack of Gas6. However, MGP was neither upregulated at the mRNA level in the aortic wall nor did we find increased differences between $\mathrm{Gas}^{-1-}$ and WT mice with respect to circulating ucMGP serum levels. Axl expression, an inhibitor of apoptosis and thus vascular calcification, was also unaltered in $\mathrm{Gas6}^{-/-}$mice. Its ligand besides Gas6, protein $\mathrm{S}$ was equal in all our in vivo groups and therefore seems unlikely to act as a counterregulator in our models.

Interestingly, $\mathrm{Gas6}^{-1-}$ mice exhibited a higher left ventricular mass despite a lower body weight. This might also partially explain why the ejection fraction after surgery in WT was significantly lower than in Gas6-/- mice (Tables 1 and 2).

Strikingly, calcium content of the myocardium was significantly lower in $\mathrm{Gas6}^{-1-}$ mice compared to WT after warfarin diet. Chemical quantification and von Kossa staining revealed only weak total myocardial calcification in $\mathrm{Gas6}^{-1-}$ and WT. Cardiac calcification is also associated with fibrosis [32] and Gas6 deficiency has been shown to prevent fibrosis [28]. Therefore, we speculate that protective effects of lack of Gas6 might depend on a different collagen content of the hearts. However, in our study, cardiac collagen staining was equal in both Gas6 and WT mice. 

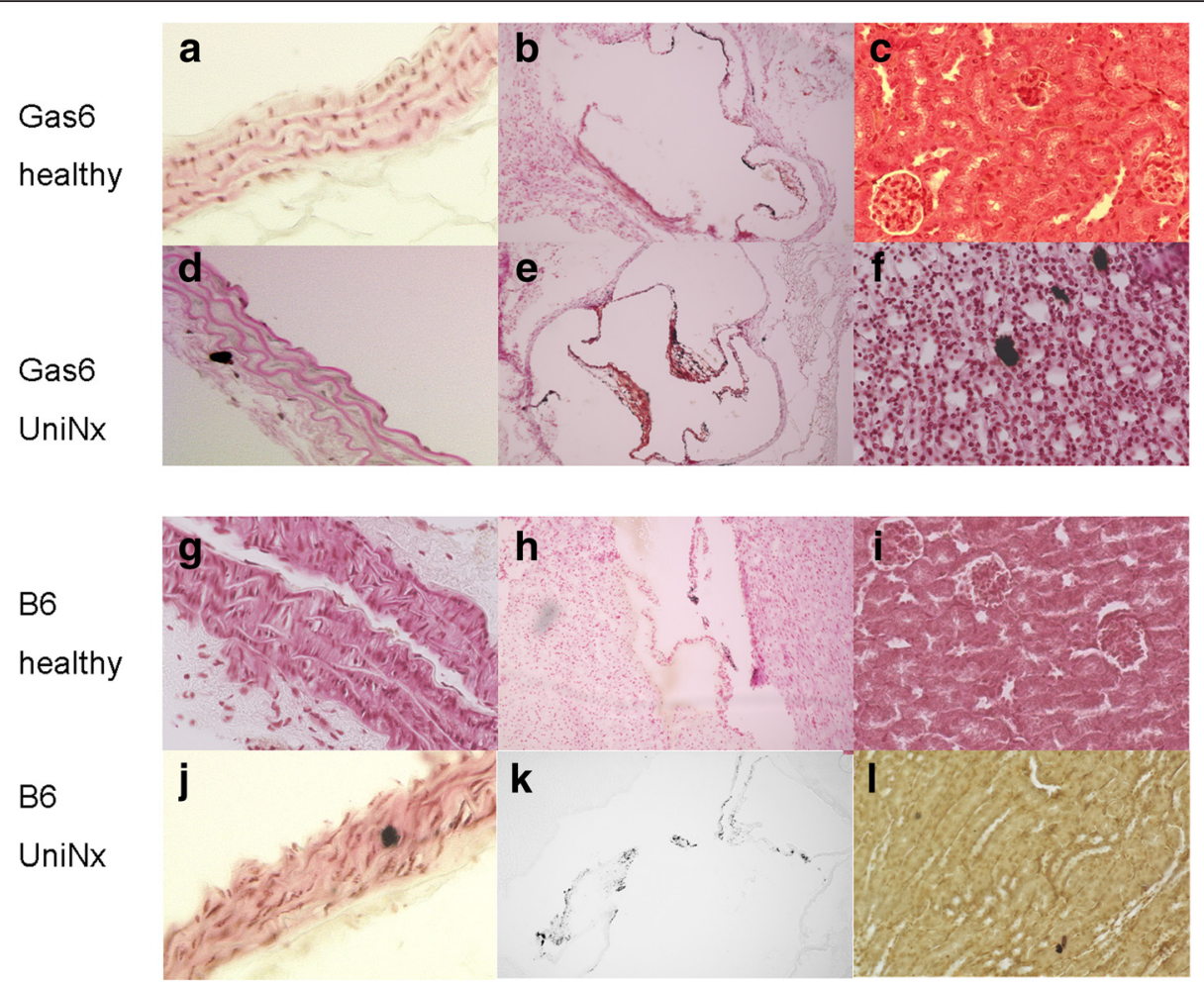

Fig. 8 Localisation of calcium deposits; Von Kossa staining of the aorta $(\mathbf{a}, \mathbf{d}, \mathbf{g}, \mathbf{j})$, heart $(\mathbf{b}, \mathbf{e}, \mathbf{h}, \mathbf{k})$ and kidney $(\mathbf{c}, \mathbf{f}, \mathbf{i}, \mathbf{I})$ after uninephrectomy in WT (Wildtype) compared to Gas6 ${ }^{-/-}$mice. WT; Magnification 400x

We observed a reduced survival of the knockout mice after electrocauterization plus UniNX compared to WT. As the mice died at different time points close to the operation procedures, calcification processes appear unlikely to be the cause of premature death. One can speculate that inflammatory processes may play a role. For example, Gas6 secretion is stimulated by TGF- $\beta$ [33] and it was found to be expressed in atherosclerotic plaques by VSMC and negatively associated with inflammation [33]. In our experiments, however, we observed neither signs of inflammation in the vessel tissue nor accumulation of

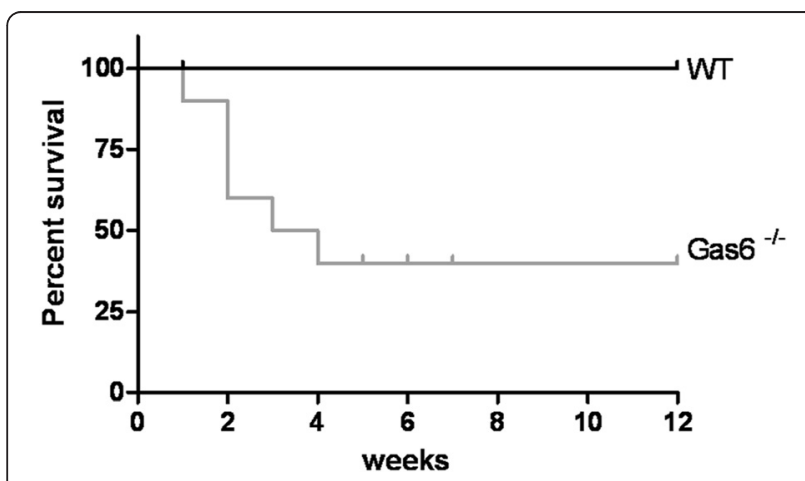

Fig. 9 Survival; Kaplan-Meier curve after electrocautery surgery in WT (Wildtype) and Gas6--mice collagen fibers in Sirius red staining. Gas6 protein was shown to enhance interactions of endothelial cells and leukocytes. Inflammation as a cause seems unlikely, as leukocyte infiltration is reduced in $\mathrm{Gas6}^{-1-}$ animals [34]. Other potential reasons could play a role in the decreased survival rate. The initial slightly lower body weight of the knockouts might hamper their survival after electrocautery. Alternatively, Gas6 knockout mice were reported to display platelet dysfunction [35] and Gas6 protein contributes to thrombus formation [23]. However, altered coagulation of the uremic $\mathrm{Gas}^{-1-}$ mice are again unlikely to have contributed to increased mortality, as we could not find evidence for hemorrhage or infarctions. Confirmatory to our results, $\mathrm{Axl}^{-1-}$ mice were recently found to have a reduced survival after renal mass reduction and high phosphate diet, but significant vascular calcification was not induced. Axl activation might reduce the progression of tubulo-interstitial apoptosis [24] and activates several cell survival factors [12].

One potential limitation of this study is the C57BL/6 genetic background of the mice. Black six mice calcify to a lesser extent than DBA/2 mice [36, 37]. With additional trigger, i.e. on top of nephrectomy, calcification in $\mathrm{B} 6$ mice is possible. Mice lacking fetuin A on a black six background (B6,129-Ahsgtm1Mbl) develop ectopic microcalcifications in soft tissues $[25,26,38]$ and only when backcrossed onto 
a DBA/2 background, does severe calcification develop [25]. Again, warfarin induced remarkable calcification in DBA/2 mice [39]. Nevertheless, in all of our models, minor calcification could be induced and the lack of aggravated calcification by depletion of Gas6 does not support a major role in vascular calcification pathogenesis.

\section{Conclusion}

Taken together, we were not able to prove a prominent role of Gas6 in vascular calcification. Further studies should confirm the role of Gas6 in disease models.

\section{Abbreviation}

BGP, Beta glycerol phosphate; EF, Ejection fraction; KH2, Vitamin K hydroquinone; LV, Left ventricular; MGP, Matrix gla protein; OPN, Osteopontin; PWV, Pulse wave velocity; UCMGP, Uncarboxylated matrix gla protein; VSMC, Vascular smooth muscle cells; WT, Wildtype.

\section{Acknowledgements}

We thank Katrin Härthe for excellent technical support.

Supported by the University Hospital of the RWTH Aachen.

\section{Funding}

The study was performed at Uniklinik RWTH Aachen, no specific funding was obtained for this study.

\section{Availability of data and materials}

All the data supporting our findings is contained within the manuscript.

\section{Authors' contributions}

NK: design, data acquisition, analysis, interpretation, drafting manuscript, final approval. SI: data acquisition, analysis, final approval. CO: data acquisition, analysis, final approval. MH: data acquisition, analysis, final approval. ND: data acquisition, analysis, final approval. PC: data acquisition, manuscript revision, final approval. CV: manuscript revision, final approval. JF: manuscript revision, final approval. TK: conception, manuscript revision, final approval.

GS: conception, writing, manuscript revision, final approval.

\section{Competing interests}

The authors declare that they have no competing interests.

\section{Consent to publish}

Not applicable.

\section{Ethics}

No statement required, as the study does not contain patients data. The animal protocol was approved by the Landesamt für Natur, Umwelt und Verbraucherschutz NRW, Germany (Permit Number 84-02.04.2011.A144).

\section{Disclosure}

\section{None to declare.}

\section{Author details}

'Uniklinik RWTH Aachen, Nephrology, Aachen, Germany. ${ }^{2}$ University of Maastricht, R\&D Group, Maastricht, Netherlands. ${ }^{3}$ University of Leuven, Vesalius Research Center, VIB, Leuven, Belgium.

Received: 3 March 2016 Accepted: 16 May 2016

Published online: 26 May 2016

\section{References}

1. London GM, Guerin AP, Marchais SJ, Metivier F, Pannier B, Adda H. Arterial media calcification in end-stage renal disease: impact on all-cause and cardiovascular mortality. Nephrol Dial Transplant. 2003;18(9):1731-40
2. Price PA, Faus SA, Williamson MK. Warfarin causes rapid calcification of the elastic lamellae in rat arteries and heart valves. Arterioscler Thromb Vasc Biol. 1998;9: 1400-07

3. Ketteler M, Rothe $H$, Krüger T, Biggar, PH, Schlieper G. Mechanisms and treatment of extraosseous calcification in chronic kidney disease. Nat Rev Nephrol. 2012;7: 509-16

4. Viegas CS, Rafael MS, Enriques JL, Teixeira A, Vitorino R, Luis IM, et al. Gla-rich protein acts as a calcification inhibitor in the human cardiovascular system. Arterioscler Thromb Vasc Biol. 2015;35:399-408

5. Shanahan CM, Cary NRB, Metcalfe JC, Weissberg PL. High expression of genes for calcification-regulating proteins in human atherosclerotic plaques. J Clin Invest. 1994;93:2394-402

6. Nakano T, Higashino K, Kikuchi N, Kishino J, Nomura K, Fujita H, et al. Vascular smooth muscle cell-derived, gla-containing growth-potentiating factor for $\mathrm{Ca}^{2+}$-mobilizing growth factors. J Biol Chem. 1995;11:5702-05

7. Lomashvili KA, Wang X, Wallin R, O'Neill C. Matrix gla protein metabolism in vascular smooth muscle and role in uremic vascular calcification. J Biol Chem. 2011;3328715-22

8. Kim H, Kim H, Lee K, Kim J, Kim H, Kim J, et al. alpha-Lipoic acid attenuates vascular calcification via reversal of mitochondrial function and restoration of Gas6/Axl/Akt survival pathway. J Cell Mol Med. 2012;16(2):273-86

9. Son B, Akishita M, llijima K, Ogawa S, Maemura K, Yu J, et al. Androgen receptordependent transactivation of growth arrest-specific gene 6 mediates inhibitory effects of testosterone on vascular calcification. J Biol Chem. 2010;285(10):7537-44

10. Manfioletti G, Brancolini C, Avanzi G, Schneider C. The protein encoded by a growth arrest-specific gene (gas6) is a new member of the Vitamin Kdependent proteins realted to protein $\mathrm{S}$, a negative coregulator in the blood coagulation cascade. Mol Cell Biol. 1993;13(8):4976-85

11. Fernandez-Fernandez L, Bellido-Martin L, Garcia de Frutos P. Growth arrestspecific gene 6 (GAS6). An outline of its role in haemostasis and inflammation. Thromb Haemost. 2008;100(4):604-10

12. Hafizi S, Dahlbäck B. Gas6 and protein S. Vitamin K-dependent ligands for the AxI receptor tyrosine kinase subfamily. FEBS J. 2006;273(23)5231-44

13. Nakano T, Kawamoto K, Kishino J, Nomura K, Higashino K, Aarita H. Requirement of gamma-carboxyglutamic acid residues for the biological activity of Gas6: contribution of endogenous Gas6 to the proliferation of vascular smooth muscle cells. Biochem J. 1997;323(Pt 2):387-92.

14. Stenhoff J, Dahlbäck B, Hafizi S. Vitamin K-dependent Gas6 activates ERK kinase and stimulates growth of cardiac fibroblasts. Biochem Biophys Res Commun. 2004:319:871-78

15. Hasanbasic I, Rajotte I, Blostein M. The role of ã-carboxylation in the antiapoptotic function of gas6. J Thromb Haemost. 2005;3(12):2790-7

16. Son BK, Kozaki K, lijima K, Eto M, Kojima T, Ota H, et al. Statins protect human aortic smooth muscle cells from inorganic phosphate-induced calcification by restoring Gas6-Axl survival pathway. Circ Res. 2006;98(8):1024-31

17. Liao X, Peng Y, Zhou X, Yang B, Zheng Z, Liu L, et al. Taurine restores Axl/ Gas6 expression in vascular smooth muscle cell calcification model. Amino Acids. 2010;39(2):375-83

18. Son BK, Akishita M, Ilijima K, Kozaki K, Maemura K, Eto M, et al. Adiponectin antagonizes stimulatory effect of tumor necrosis factor-alpha on vascular smooth muscle cell calcification: regulation of growth arrest-specific gene 6-mediated survival pathway by adenosine 5'-monophosphate-activated protein kinase. Endocrinology. 2008;149(4):1656-53

19. Angelillo-Scherrer $A$, Burnier $L$, Lambrechts $D$, Fish RJ, Tjwa M, Plaisance $S$, et al. Role of Gas6 in erythropoiesis and anemia in mice. J Clin Invest. 2008;118:583-96

20. Gagnon RF, Duguid WP. A reproducible model for chronic renal failure in the mouse. Urol Res. 1982;11:11-14

21. Smith PK, Krohn RI, Hermanson GT, Mallia AK, Gartner FH, Provenzano MD, et al. Measurement of protein using bicinchoninic acid. Anal Biochem. 1985:150:76-85

22. Cranenburg ECM, Koos R, Schurgers LJ, Magdeleyns E, Schoonbrood THM, Landewe $\mathrm{R}$, et al. Characterization and potential diagnostic value of circulating matrix Gla protein (MGP) species. Thromb Haemost. 2014;104:811-22

23. Robins RS, Lemarié CA, Laurance $S$, Aghourian MN, Wu J, Blostein MD. Vascular Gas6 contributes to thrombogenesis and promotes tissue factor up-regulation after vessel injury in mice. Blood. 2013;121(4):692-6

24. Hyde GD, Taylor RF, Ashton N, Borland SJ, Wu HSG, Gilmore AP, et al. Axl tyrosine kinase protects against tubulo-interstitial apoptosis and progression of renal failure in a murine model of chronic kidney disease and hyperphosphataemia. Plos One. 2014;9(7):e102096

25. Schaefer C, Heiss A, Schwarz A, Westenfeld R, Ketteler M, Floege J, et al. The serum protein alpha 2-Heremans-Schmid glycoprotein/fetuin-A is a 
systemically acting inhibitor of ectopic calcification. J Clin. Invest. 2003; 11(3):357-66

26. Westenfeld R, Schaefer C, Smeets R, Brandenburg VM, Floege J, Ketteler M, et al. Fetuin-A (AHSG) prevents extraosseous calcification induced by uraemia and phosphate challenge in mice. Nephrol Dial Transplant. 2007;22: $1537-46$

27. Schlieper G, Westenfeld R, Krüger T, Cranenburg E, Magdeleyns E, Djuric Z, et al. Circulating nonphosphorylated carboxylated matrix gla protein predicts survival in ESRD. J Am Soc Nephrol. 2011;22(2):387-95

28. Fourcot A, Couchie D, Chobert MN, Zafranini ES, Mavier P, Laperche Y, et al. Gas6 deficiency prevents liver inflammation, statogepatitis, and fibrosis in mice. Am J Physiol Gastrointest Liver Physiol. 2011;300:G1043-53

29. Schurgers LJ, Spronk HM, Skepper JN, Hackeng TM, Shanahan CM, Vermeer C, et al. Post-translational modifications regulate matrix Gla protein function: importance for inhibition of vascular smooth muscle cell calcification. J Thromb Haemost. 2007;5(12):2503-11

30. Shanahan CM, Crouthamel MH, Kapustin A, Giachelli CM. Arterial calcification in chronic kidney disease: key roles for calcium and phosphate. Circ Res. 2011;109:697-711

31. Clarke MCH, Littlewood TD, Figg N, Maguire JJ, Davenport AP, Goddard M, et al. Chronic apoptosis of vascular smooth muscle cells accelerates atherosclerosis and promotes calcification and medial degeneration. Circ Res. 2008;102(12):1529-38

32. Merx MW, Schafer C, Westenfeld R, Brandenburg V, Hidajat S, Weber C, et al. Myocardial stiffness, cardiac remodeling, and diastolic dysfunction in calcification-prone fetuin-A-deficient mice. J Am Soc Nephrol. 2005;16(11): 3357-64

33. Clauser S, Meilhac O, Bièche I, Raynal P, Bruneval P, Michel JB, et al. Increased secretion of Gas6 by smooth muscle cells in human atherosclerotic carotid plaques. Thromb Haemost. 2012;107:140-9

34. Tjwa M, Bellido-Martin L, Lin Y, Lutgens E, Plaisance S, Bono F, et al. Gas6 promotes inflammation by enhancing interactions between endothelial cells, platelets, and leukocytes. Blood. 2008;111(8):4096-105

35. Angelillo-Scherrer A, Garcia de Frutos P, Aparicio C, Melis E, Savi P, Lupu F, et al. Deficiency or inhibition of Gas6 causes platelet dysfunction and protects mice against thrombosis. Nat Med. 2001;7(2):215-21

36. Moe SM. Vascular calcification: the three-hit model. J Am Soc Nephrol. 2009; 20:1162-64

37. van den Broek FAR, Beynen AC. The influence of dietary phosphorous and magnesium concentrations on the calcium content of heart and kidneys of DBA/2 and NMRI mice. Lab Anim. 1998;32:483-91

38. Jahnen-Dechent W, Schinke T, Trindl A, Müller-Esterl W, Sablitzky F, Kaiser S, et al. Cloning and targeted deletion of the mouse fetuin gene. J Biol Chem. 1997:272(50):31496-503

39. Krüger T, Oelenberg S, Kaesler N, Schurgers L, van de Sandt A, Boor P, et al. Warfarin induces cardiovascular damage in mice. Arterioscler Thromb Vasc Biol. 2013;33(11):2618-24

\section{Submit your next manuscript to BioMed Central and we will help you at every step:}

- We accept pre-submission inquiries

- Our selector tool helps you to find the most relevant journal

- We provide round the clock customer support

- Convenient online submission

- Thorough peer review

- Inclusion in PubMed and all major indexing services

- Maximum visibility for your research

Submit your manuscript at www.biomedcentral.com/submit

) Biomed Central 